\title{
PARTICIPATION AND VOICE OF WOMEN IN COMMUNITY-BASED ORGANIZATION (A SPECIAL REFERENCE TO MATHAGAL EAST RURAL WATER SUPPLY)
}

\author{
Cavitha Balachandran* \\ University of Jaffna, Sri Lanka
}

\begin{abstract}
Participation of Women in Community-Based Organizations has the significance for the controlled access of community resources, enhanced decision-making and chipping away at sociocultural norms that constrain the voice of women. Women empower the Programmes managed by the community with an initial support from the government or international organization are considered as the useful strategy to provide safe drinking water to the rural communities in the world to achieve the "gender equality", sustainable development goal of UN. Across the developing countries, studies show that the Women are active participants in CBOs but they are still underrepresented in leadership positions and entrenched traditional views and cultural practices continue to restrict their public roles. This research aims to identify the participation and capability of women in community-based organizations to manage rural water supply. Furthermore, this study tends to propose some recommendations to enhance the women participation in CBOs. Primary data were collected by field observation, interview, questionnaire survey and discussion methods and secondary data were obtained from different official sources. Research samples were selected through Simple Random sampling method. Descriptive statistical analysis was used for this study. The study concludes that the women participate actively in CBOs during various stages and hold higher positions in the CBOs. Women in the CBOs are capable to manage the rural water supply with sustainability. Poor education and leadership, socio cultural influences, domestic and family responsibilities and religious beliefs are some factors hindering the women's participation in CBOs. Some useful recommendations are proposed here to enhance women's participation in CBOs. These findings help the researchers, planners, policy makers and graduates to advance women's participation in CBOs.
\end{abstract}

Keywords: Women Participation, Community Based Organizations, Rural Water Supply

\section{Introduction}

\section{Background of the study}

Participation of Women in Community-Based Organizations has significance for the controlled access of community resources, enhanced decision-making and chipping away at socio-cultural norms that constrain women's voice (Asian Development Bank Report, 2014). Women empower the programmes managed by the community with an initial support from governments or international organizations which are considered as the useful strategy to provide safe drinking water for the rural communities in the world to achieve the "gender equality", sustainable development goal of United Nations.

The importance of involving women in the management of water and sanitation has been recognized universally at the United Nations Water Conference at Mar del Plata in 1977. Following that, the International Drinking Water and Sanitation Decade (1981-1990) and The International Conference on Water and the Environment in Dublin (January 1992) explicitly recognize the central role of women in the provision, management and safeguard of water. The United Nations conference on Environment and Development in Rio de Janeiro, the World Summit on Sustainable Development in Johannesburg and the Water for Life 
Decade (2005-2015) calls for women's participation and involvement in water related development efforts (United Nations Water Report, 2006). The Millennium Development Goals and the Sustainable Development Goals have the close interlinkages between gender equality and women's empowerment and the access to water and sanitation.

International Water and Sanitation Centre and World Bank Studies found that projects are designed and run with the full participation of women which are more sustainable and effective (United Nations Water Report, 2006). Wallace and Coles (2005) states that efficient participation tools that encourage the female participation within the water management at all societal levels constitutes a vital element for promoting sustainable and efficient water supply management and distribution. Across the developing world studies show that the women are the active participants in Community-Based Organizations such as water user groups, sanitation committees, farmer groups, loans and savings groups, and irrigation user groups (Asian Development Bank Report,2014). However, they are still underrepresented in leadership positions and entrenched in traditional views and cultural practices which continue to restrict their public roles. According to Wilson (2009), it is apparent that the progress towards women participation in development has encountered obstacles at the institutional level all over the world.

Among traditional societies of the world, men and women were assigned for various roles (Start, 2008). In most cultures, women have the primary responsibility for the use and management of water resources and for sanitation and health at the household level. Women and girls are often obliged to walk many hours every day fetching water while men are almost never expected to perform such tasks. Yet the water facilities are provided without the involvement of women, who want the facilities properly. Despite they are denied to come out with their opinions in relation to water and sanitation and the services they receive. Women and children suffer a lot to fetch water as they commonly carry it for domestic purposes as they are responsible for these (Karolin Svahn,2011).

In the post era of the thirty years of ethnic war, the drinking water has become a serious issue in Jaffna Peninsula. Ground water is the only natural resource and it is often polluted due to sea water intrusion into the fresh water lens, nitrate pollution through the continuous use of organic manure and inorganic fertilizers, improper planning of soakage pits and latrines (Nanthini, Mikunthan, Vijayaratnam,2000). High incidence of water borne diseases are reported in the surveys, including diarrhea, dysentery, typhoid, hepatitis, parasitic infections, and skin rashes, during the rainy season especially for women and children (Asian Development Bank Report, 2011). Mostly women and children in rural areas, spent up to four hours per day walking 3-6 kilometers to fill the containers with water (Asian Development Bank Report, 2011). In this situation, National Water Supply and Drainage Board has implemented the Community Based Water Supply and Sanitation Project for the first time to reduce poverty, empower the women and improve the quality of life in post-conflict rural communities in Jaffna and Kilinochchi districts through women participation and Water Supply and Sanitation (WSS) services in order to achieve Millennium Development Goals and the Sustainable Development Goals. However, there are insufficient studies conducted in Jaffna peninsula regarding Gender and water management. Thus this study gets its significance to evaluate the women participation in community-based organizations and community-based development projects.

\section{Statement of the problem}

The effective participation of women is strongly associated with water supply and the effectiveness and sustainability sanitation project. Across the developing countries, the studies in Gender and Development show that the Women are willing to participate actively in Community Based Organizations but the traditional views and cultural practices continue to restrict their public roles and leadership positions. The participation of women in community - based is a serious challenge that the developing countries governments and foreign donors are facing when starting community-based water supply and sanitation projects. This study involved with participation and capability of women in community-based organizations to manage rural water supply, challenges and possible recommendations to activate women participation in Community Based Organizations. 


\section{Objectives of the study}

The main objective of the study is to identify the participation and capability of women in community-based organizations to manage rural water supply

Second one tends to propose some recommendations to enhance the women participation in community-based organizations and execute water supply efficiently.

\section{Significance of the study}

The findings of the study contribute to enhance the women's participation in different phases of communitybased development projects and empower the capability of women in community-based organizations to manage rural water supply efficiently.

These research findings are helpful to the Governmental organizations, Non-governmental organizations, Academicians, Researchers, Policy makers and Planners to advance women's participation in development projects

\section{Limitations of the study}

In undertaking the study, a number of limitations were encountered -:

Community Based Water Supply and Sanitation project implemented in Vaddakachchi, Akkarayan, Mathagal East, Delft, Shanthai divisions, even though this study only involved women participation in communitybased organizations in Mathagal rural water supply. The second limitation was attributed to the authentication of the information given by the respondents. Majority of the respondents were reluctant to give detailed information. Some attempted to conceal crucial and correct facts, while others shy away from responding to the questionnaire. The third limitation was attributed to the sample size and generalization of the findings.

\section{Research Area}

Mathagal East is a coastal area situated $16 \mathrm{Km}$ away from Jaffna Town in the North of Sri Lanka, to the North West of Jaffna. It has an area of 1.81 square kilometers and surrounded by Mathagal Sea, Mathagal South, Mathagal West and Mareesankoodal and consists eleven parts. Agricultural lands, settlements, shrubs and waterbodies are the major land use of this area and majority of the people engaged in Agricultural and fisheries sectors. According to the statistical handbook of the Vali south west divisional secretariat only 33 percentages of people access the safe drinking water and 84 percentages access to the basic sanitation facilities. Most of the wells in research area only use for the secondary purposes due to the salinity problem. The census conducted by the Department of Census and Statistics shows the Mathagal East is having 1075 male population and 1119 female population in the year 2017. Mathagal East Rural Development Association, Thuraimugam Rural Development Association, Sahayapuram Rural Development Association, Pukkaipulo Women Association for Rural Development, Mathagl East Youth Club, Mathagal East Farmers Association, and Navalar Community Development Center are the community-based organizations in the research area that involve in community-based development projects. 


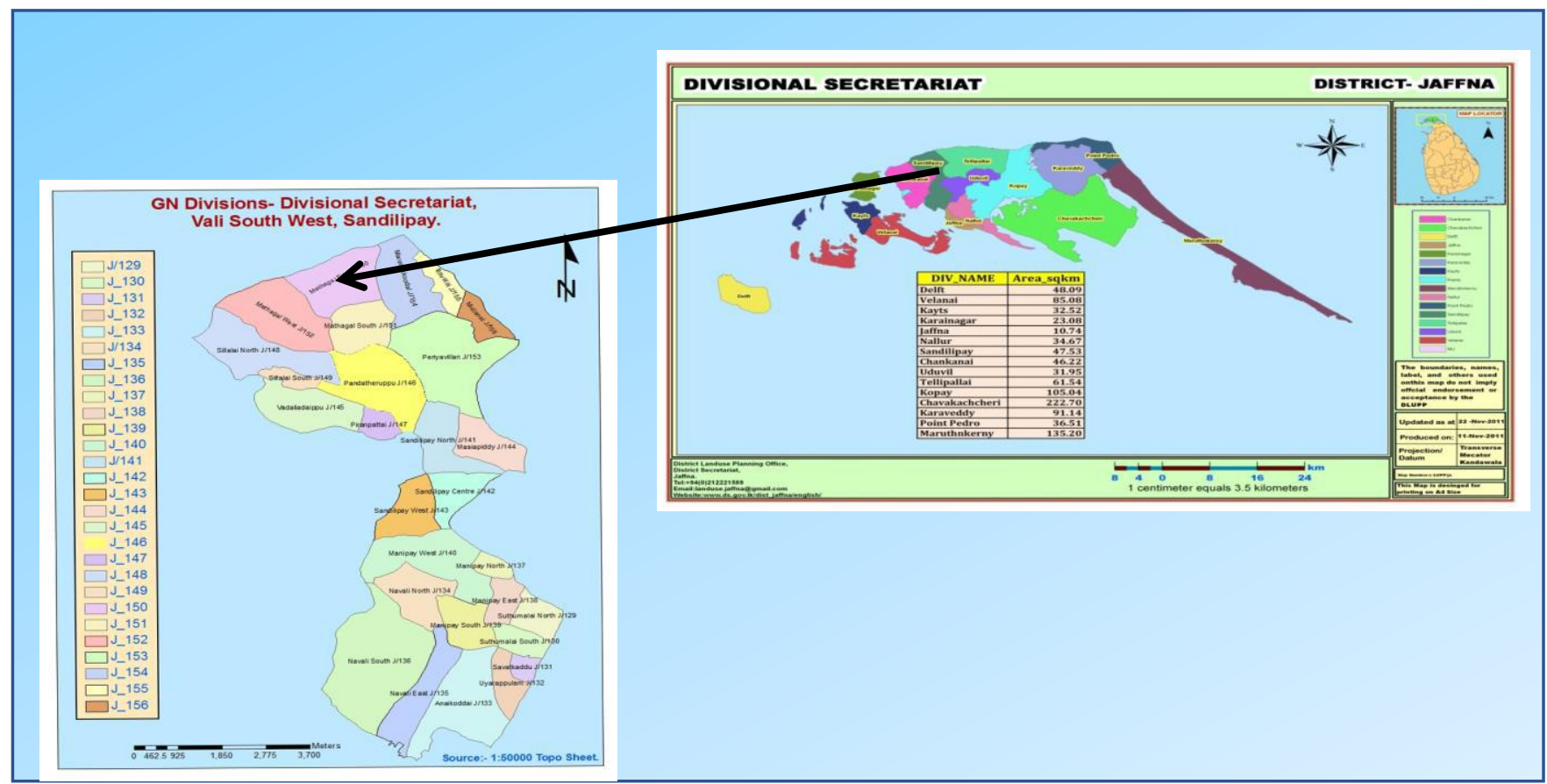

Figure 01: Map of Research Area

Source- http://www.valikamamsw.ds.gov.lk

\section{Methodology of Research}

Primary and Secondary data were used for this study. Primary data was collected by Field observation, Interview, Questionnaire survey, discussion methods and secondary data was obtained from report of Asian Development Bank, pamphlets of National Water Supply Drainage Board, Statistical hand book of Valikamam South West Divisional Secretariat, report of Mathagal East Water User Committee. All the members in CBOs were selected for this study. Research samples (100 samples) were selected from women beneficiaries through Simple Random sampling method and NWSDB officers from Non-probability sampling. Descriptive statistics was used for this study. The data collected through questionnaire survey have been analyzed using MS excel software 
This diagram shows the sampling size of women Beneficiaries

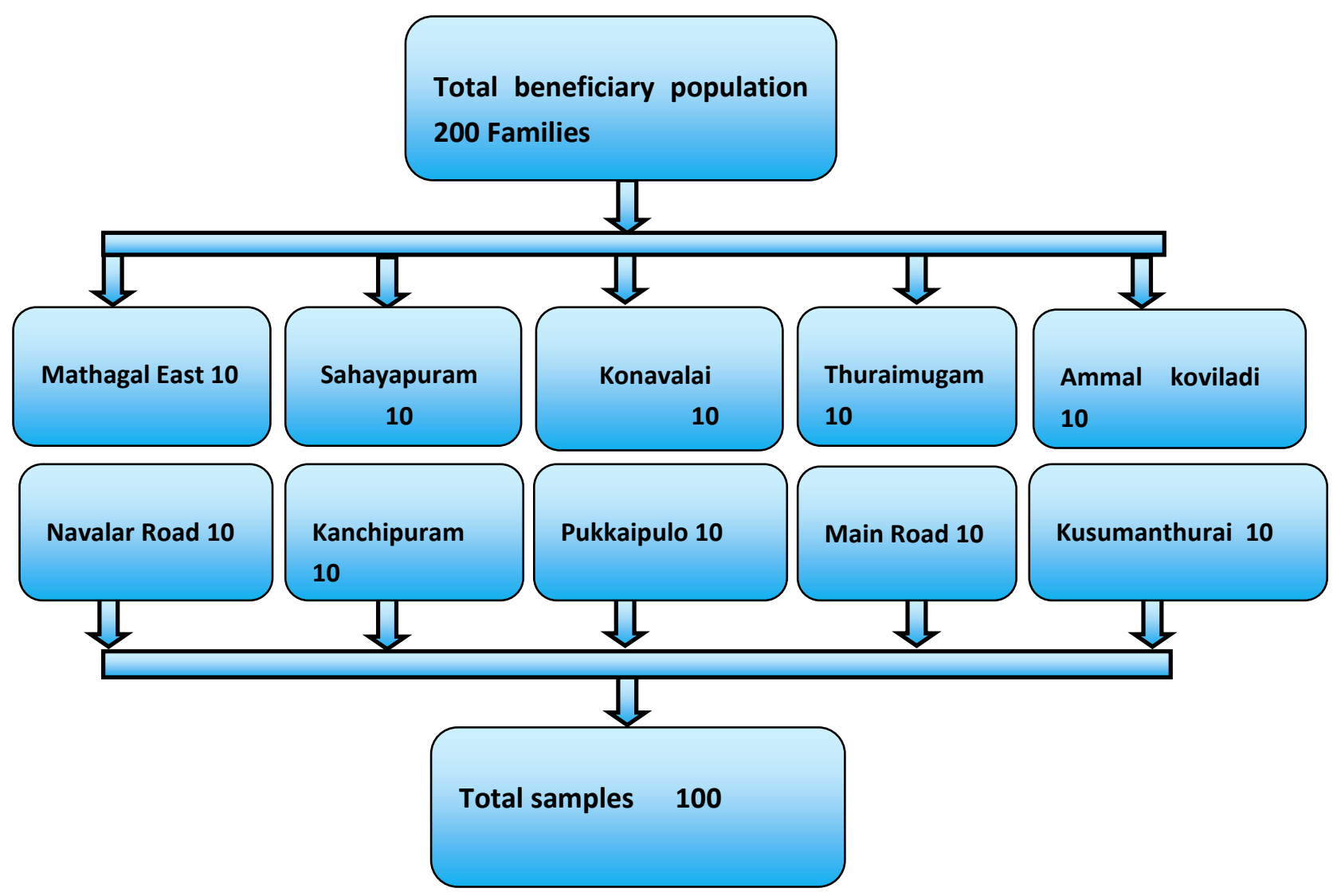

This diagram shows the sampling size of NWSDB officers

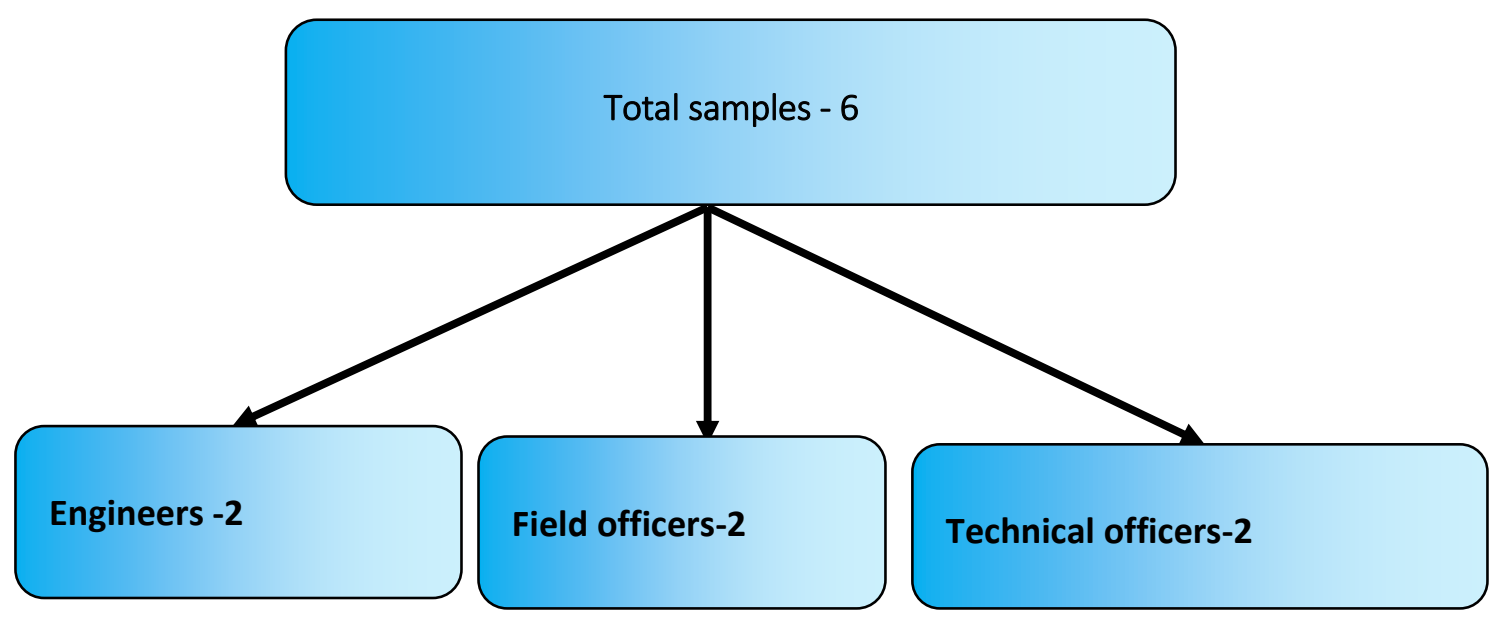

Source- By researcher (2017) 
Cavitha Balachandran / Participation And Voice Of Women In Community-Based.....

\section{Methodology of Research}

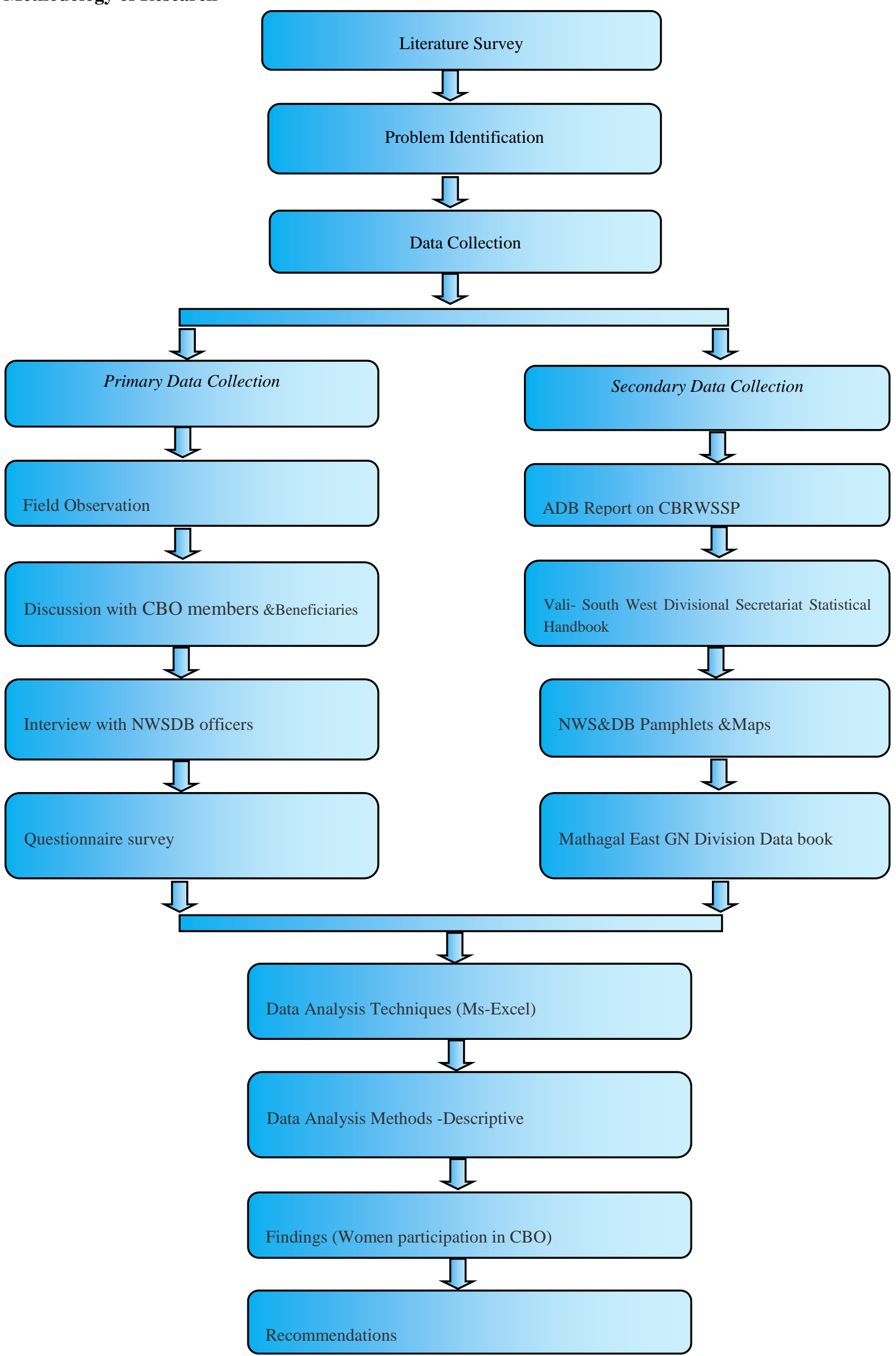




\section{Data Analysis and Findings}

Pukkaipulo Women Rural Development Committee and Mathagal East water user committee are the key community-based organizations for the rural water supply in this research area.

\section{Details of the female respondents in Community Based Organization}

It is very important to identify the demographic characteristics of the respondents to achieve the desired responses in the study.

\section{Age range of the female respondents in Community Based Organization}

Age is a very important variable in influencing the demographic characteristics of the respondent. 30 percentages of the respondents are in 20 to 30 years, 40 percentages of the respondents are in 31 to 40 years, while those above 41 years.

\section{Gender role in Community Based Organization}

Gender means socially constructed roles, behaviors, activities and attributes which a particular society consider that is appropriate for men and women. 100 percentages of committee members are female in Pukkaipulo Women Rural Development Committee and 60 percentages of the committee members are male while 40 percentages are female in Mathagal water user committee. This study is mainly concerned with female committee members; however, there was a need to get some ideas from men who works closely with women especially in women enterprise development.

\section{Highest level of Education}

Education improves the ability of a person to think critically and understand the issues. Active involvement in organizational activities depended mainly on education. 40 percentages of the female members who had primary education, 30 percentages had secondary education and 20 percentages of them had tertiary education. This suggests that all the respondents should have at least basic education and its assumed that they could make any decisions.

\section{Service Experience of the female members in Community Based Organization}

40 percentages of the female committee members have less than one-year service experience, 34 percentages of them have two-year service experiences, 6 percentages of them have 6 years and 20 percentages of them have more than 20 years' service experience in Community Based Organization.

\section{Women Participation in Community Based Organization during the different phases of Mathagal East community based rural water supply and sanitation project}

As a result of analyzed data, this research findings emphasized female committee members highly involved in community-based organizations during the planning, designing, decision making, implementing stages and slightly engaged in operation and maintenance stages of community based rural water supply and sanitation project. Pukkaipulo Women Rural Development Committee and Mathagal East water user committee are the key community-based organizations for the rural water supply in this research area. More than 60 percentages of the female committee members stated that they are holding many positions in Community Based Organization as president, secretary, treasurer, members, team leader for construction works, organizer for meetings, awareness programs and medical camps and monitor for operation and maintenance work. 


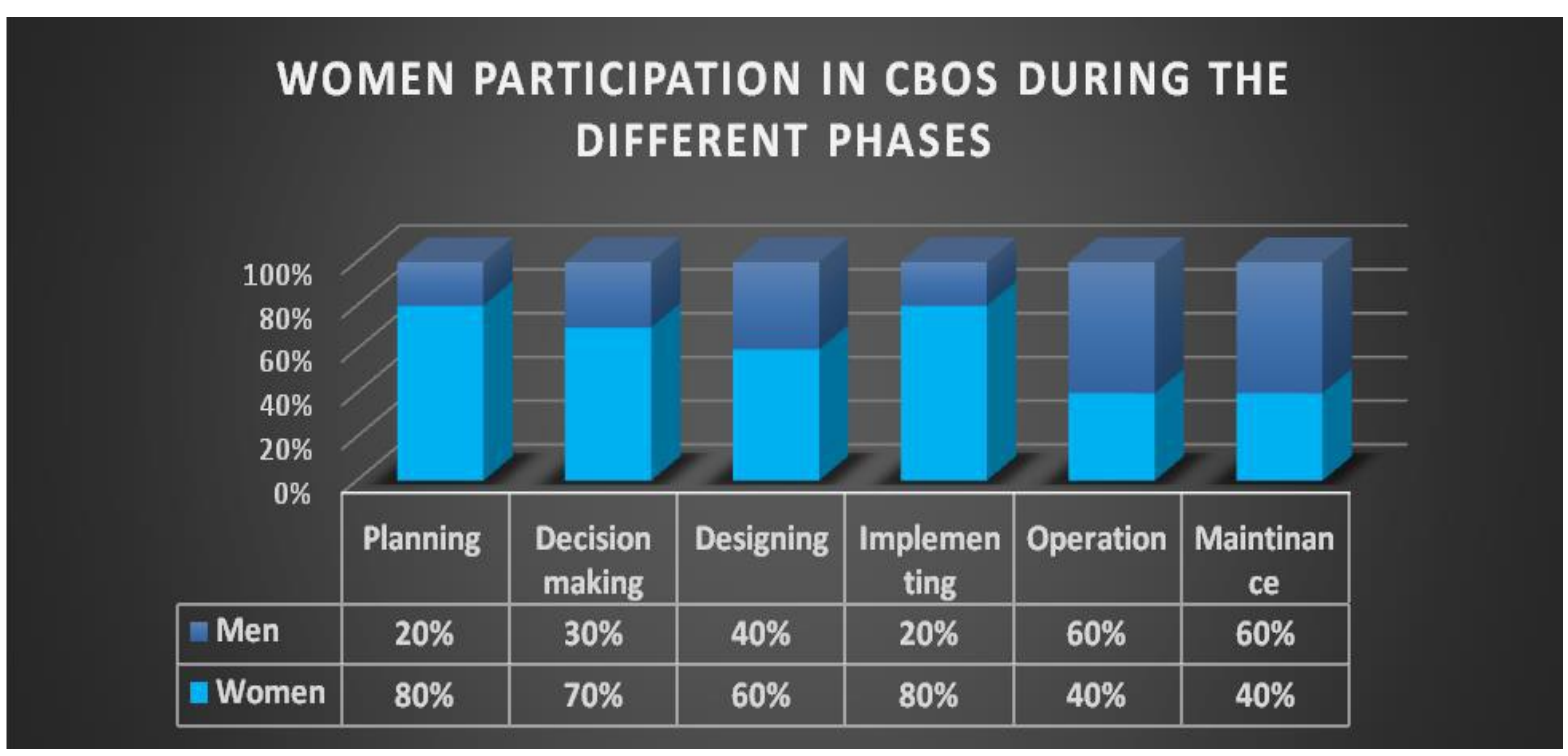

Figure 02: Women Participation in Community Based Organization during the different phases of Mathagal East community based rural water supply and sanitation project

Source- Questionnaire survey (2017)

The above figure shows that more than 70 percentages of women in community-based organization actively participated in the planning and decision-making stages which are considered the most important phase of the project success.

60 percentages of female committee members actively involved in the discussions and meetings regarding the location and design of the water supply facilities during the designing phase such as design the water tower stand posts, common taps and pipelaying.

Nearly 80 percentages of female committee members from community-based organization stated that they were involved in the construction works such as construction of well, water pumping station, meter room, valve room and chlorinity room in Periyavilan, pipelaying through Uyarapulam road and Anthoniyar road to water tower, water tower construction at Pallakulam, construction of thirty stand posts, fitting solar panel and latrine construction under cash for work programme. Most women from women rural development committee contributed by cooking and bringing the meals to the construction site workers who engaged with digging land, earth filling and construction of well tasks. Some female committee members perform some preparation tasks before the construction phase such as cleaning the well construction and tower construction sites, removing the unwanted stones and bushes in the road site where the community need to lay the pipes. Most of the female committee members were participated in the implementation stage as volunteers.

40 percentages of female committee members engaged in operation activities of rural water supply such as providing water supply in regular basis and repairing water pumps, pitting damaged pipes and solve the technical problems. 40 percentages of women involve with maintenance, monitoring activities and managing the water supply in sustainable manner. They are responsible for monitoring the 30 stand posts in the water supply time for preventing the waster of water and water pollution. In the same time, they prepare the water bills and collecting monthly water fees, maintaining bank accounts, book keeping, pay the payment for the services monitoring water quality and conducting meetings and awareness Programmes. 


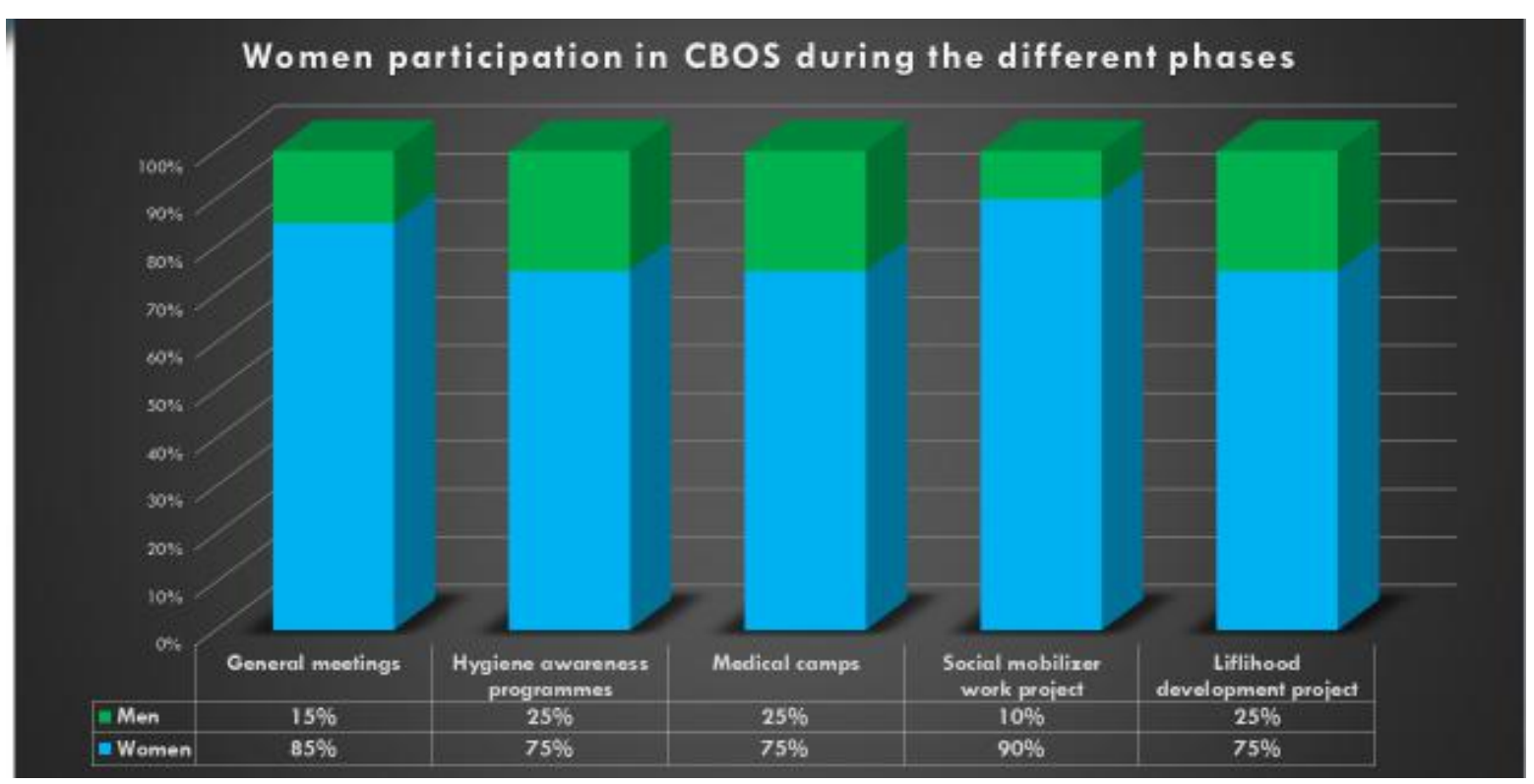

Figure 03: Women participation in Community Based Organization during the different phases community based rural water supply and sanitation project

Source-Mathagal water user committee reports (2017)

The study found that more than 75 percentages of female committee members were actively involved in organizing and participating in the general meetings, hygiene awareness Programmes, health clinics, women and social empowerment Programmes in school and social level with the proper guidance of National Water Supply and Drainage Board, Sevalanka and Health ministry. Most of the women in Community Based Organization participated in the livelihood development Programmes such as Jam production and Palmyra based production. As the same time 10 of the female committee members actively worked as social mobilizers for creating social maps.

\section{Assess the Capability of female committee members to manage rural water supply schemes}

Table 01: capability of female committee members to manage rural water supply schemes

\begin{tabular}{|l|l|l|l|}
\hline Skills and Abilities & More capable & Partially capable & Less capable \\
\hline Technical skills & \multicolumn{2}{|l|}{} \\
\hline Operation and maintenance & $60 \%$ & $20 \%$ & $20 \%$ \\
\hline Repairing & $10 \%$ & $20 \%$ & $70 \%$ \\
\hline Monitoring & $70 \%$ & $20 \%$ & $10 \%$ \\
\hline Administrative skills & & & \\
\hline Collecting water fees & & $10 \%$ & $10 \%$ \\
\hline Maintaining Bank Accounts & $60 \%$ & & $20 \%$ \\
\hline Book Keeping & $80 \%$ & $20 \%$ & $10 \%$ \\
\hline Pay the payment for services & $70 \%$ & $10 \%$ & $10 \%$ \\
\hline
\end{tabular}




\begin{tabular}{|l|l|l|l|}
\hline Personality skills & \multicolumn{3}{|l|}{} \\
\hline Problem solving & $70 \%$ & $20 \%$ & $10 \%$ \\
\hline Planning & $60 \%$ & $20 \%$ & $20 \%$ \\
\hline Leadership & $70 \%$ & $20 \%$ & $10 \%$ \\
\hline Decision making & & & $20 \%$ \\
\hline
\end{tabular}

Source- Questionnaire survey (2017)

\section{Factors hindering women participation in Community Based Organization during the operation and maintenance stages}

Women participation in Community Based Organization has been hindered or affected by several factors. 50 percentages of respondents said that the long period war and its effects and internal political situation is the main obstacle for the empowerment of women in research area. 40 percentages of respondents' state that as a result of these domestic and family responsibilities many women are not ready socially, intellectually and politically. This leads to low confidence and lack of self-esteem. 30 percentages of them stated that socio cultural influences are very strong tools for hindering women participation in Community Based Organization. Such social norms and behaviors are the determining factor of the behavior of the society and capture the mindset of people especially in rural areas. In the point of view of 30 percentages of respondents that the lack of experience is the key factor for the hesitation of women to take leadership roles. Women themselves shy away from taking up leadership challenges and our society does not give a chance to women to participate in Community Based Organization. 20 percentages of respondents' state that the biggest obstacles to women becoming empowered are their own attitude and lack of confidence in their abilities. From our traditional culture and belief that men are superior to women and therefore the decision makers. 10 percentages of them stated that lack of education and unawareness of hygienic practices, women empowerment are the hindering factors for the women participation in Community Based Organization. Religion is an integral part of society and it has been used as a tool for social control. 10 percentages of respondents' state that religious beliefs creating a barrier to women's participation in development activities in research area.

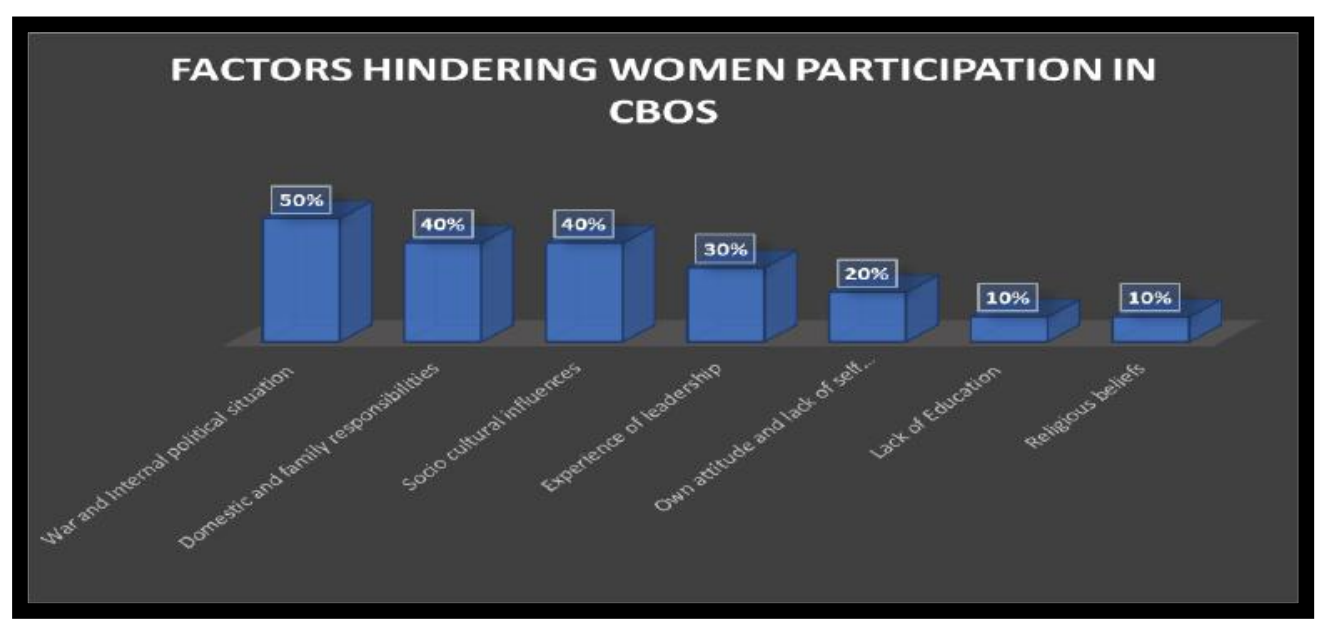

Figure 04: Factors hindering women participation in Community Based Organization

Source-Questionnaire survey (2017) 


\section{Recommendations}

In view of the above Findings this study proposes the following recommendations to enhance the women participation in community-based organizations to execute water supply efficiently

- $\quad$ Setting female quotas for women participation in community user groups can help to slowly chip away the social norms and confront cultural barriers to facilitate women' effective membership and leadership of Community Based Organization and create the space for women' entry into the public space of community decision making

- Complementary Capacity building initiatives such as leadership, advocacy and facilitation training and workshops are required to build women's technical administrative, personality skills and contributed to their social empowerment and mobilization

- Make sure that sector meetings at community level are organized to overcome socio cultural and religious barriers to women's participation in Community Based Organization

- Providing technical training, financial training, administrative training to the female committee members of Community Based Organization to manage rural water supply in sustainable manner

- Increasing the participation of young, energetic, knowledgeable, skillful female committee members in Community Based Organization

- Conduct effective environmental conservation Programmes, hygiene awareness workshops, gender awareness workshops and women empowerment Programmes in community and school level to give awareness regarding the safe drinking water, sanitation practices and empower the women in rural areas

- Promote that operational agencies to provide information for decision making on policies, strategies, plans and investments that accessible to women and marginalized groups

\section{Importance of women's' participation in Community Based Organizations}

World Commission on Environment and Development (WCED) points out that the "Development that meets the needs of the present without compromising the ability of future generations to meet their own needs" is sustainable development. For attaining the sustainable development, women need to be empowered for active participation in Community based development projects. Empower women for leadership is an essential need that gives them the courage needed for participating in Community Based Organization and worked as a manager of the human and financial resources of an organization, an organizer, mobilizer, motivator, producer, communicator, and planner.

Participation of women in Community Based Organization is necessary because of "the essence of participation is exercising voice and choice and developing the human, organizational and management capacity to solve problems as they arise in order to sustain the improvement" (Zablon Bundi Mutongu,2012). The active participation of women is strengthening women's ability to make decisions, accomplish tasks effectively and maximize the outcomes of their efforts (Zablon Bundi Mutongu,2012). The United Nations Economic Commission for Latin America and the Caribbean (ECLAC) states, "women at all levels of responsibility have always been involved in activities for the improvement of the quality of life of their families and communities.

\section{Conclusion}

The study concludes that the women participate actively and hold higher positions in the Community Based Organization during the various stages of Mathagal Water supply and Sanitation Project. The female committee members in the Community Based Organization have technical, administrative and personality skills significantly and capable to manage the rural water supply in sustainable manner. However Poor education, lack of leadership experience, socio cultural influences, domestic and family responsibilities, long time war and internal political situation and religious beliefs are some factors hindering the women's participation in Community Based Organization. These findings help the researchers, planners and policy 
makers to empower the women capacity and advance their participation in Community Based Development Projects. In the same time this research has attracted research attentions especially in the field of water, sanitation and hygiene, gender equality.

Furthermore, there is a need to analyze the linkage between the active participation of women and the effectiveness of community Based Development projects. Another area which needs to be study further that the positive outcomes of participating women in the different stages of community-based development projects and the factors influencing women participation in community-based development projects.

\section{References}

Wijk-Sijbesma, Christine van (1985), "Participation of women in water supply and sanitation: roles and realities", The Hague, The Netherlands.

Elizabeth Laboso (2014), "Factors influencing women participation in community based development projects: a case study of bureti sub-county, kericho county", University of Nairobi.

Zablon Bundi Mutongu (2012), “Women's Participation in Community-Based Organizations' Development as a Strategy for Poverty Reduction in Kenya", PRISCILLA PAPERS The academic journal of CBE International, Journal Volume: 26 ,Issue Number: 1

Mimrose.S, Gunawardena.N, Nayakakorala.B (2011), "Assessment of Sustainability of Community Water Supply Projects in Kandy District", University of Peradeniya, Srilanka.

$$
\text { P 51-60 }
$$

Wijesundara.P (December 2008), "Study on CBOs Capability for Sustainable Management of Rural Water Supply Schemes", Department of Civil Engineering, University of Moratuwa, Srilanka.

Muthunayake.S (2010), "Success Factors for Effective Management of Rural Water Schemes in Srilanka", Department of Civil Engineering, University of Moratuwa, Srilanka.

Richard C Carter, C Geol., Sean F Tyrrel, Peter Howsam (August 1999), "Impact and Sustainability of Community Water Supply and Sanitation Programmes in Developing Countries", Institute of Water and Environment, Cranfield University at Silsoe. P 292-296

Rita Padawangi (August 2009), "Community- Driven Development as Drivers of Change: Water Supply and Sanitation Projects in Rural Punjab, Pakistan", Institute of Water Policy, Lee Kuan Yew school of Public Policy, National University of Singapore.

William Mwakila (December 2008), "An Assessment of Community Participation in Water Supply and Sanitation Services: The Case of Yombo Dovya and Barabara ya Mwinyi , Water Community Projects, Temeke, Tanzania”, Institute of Social Studies, 2502 LT The Hague, Netherlands.

T. Nanthini, T.Mikunthan, R.Vijayaratnam(2000), "Some Physico-chemical characters of ground water in some (selected) water supply wells in the Jaffna Peninsula", Jounal of the National Science Foundation SriLanka.

Andrea C. Telmo (2002), “ A Water Supply and Sanitation Study of the Village of Gouansolo in Mali, West Africa”, Michigan Technological University.

Holly Sanders \& Jennifer Fitts (May 2011), “Assessing the Sustainability of Rural Water Supply Programs: A Case Study of Pawaga, Tanzania".

Firminus Mugumya (2013), "Enabling Community- Based Water Management Systems: Governance and Sustainability of Rural Point- Water Facilities in Uganda", School of Law and Government, Dublin City University.

Elias Onesmo Mtinda (December 2006), "Sustainability of Rural Water Supply and Sanitation Services Under Community Management Approach: The Case of Six Villages in Tanzania", Department of Water and Environmental Studies, Linkopings Universitet.

Habtamu Addis Beyene (2012), "Factors Affecting the Sustainability of Rural Water Supply Systems: The Case of Mecha Woreda, Amhara Region, Ethiopia", Faculty of the Graduate school of Cornell University.

Kennedy Musonda ( February 2004), "Issues Regarding Sustainability of Rural Water Supply in Zambia”, The University of South Africa.

Julie A. True love (June 2003), "Sustainability of Community Managed Rural Water Supply in Post-Conflict Regions of Northern Uganda", WEDC Resources Centre, Loughborough University. 
Christopher Dale Peltz (May 2008), "Community Water Supply: Project Effectiveness and Sustainability" Colorado State University Fort Collins, Colorado.

Shanthasiri .S, Wijesooriya. R (2004), "People-Centred Approaches to Water and Environmental Sanitation Case Study on Community Involvement in Rural Water Supply Srilanka", $30^{\text {th }}$ WEDC International Conference, Vientiane.

W.Ediriweera (2005), "Maximizing the Benefits from Water and Environmental Sanitation- Strategies Adopted for Sustained Water Supply and Sanitation through Community Participation in Srilanka", 31st WEDC International Conference, Kampala, Uganda.

Asian Development Bank (January 2011), "Proposed Grant Assistance, Democratic Socialist Republic of Sri Lanka: Improving Community-Based Rural Water Supply and Sanitation in Post-Conflict Areas of Jaffna and Kilinochchi”, Project Number - 44082

Asian Development Bank(June 2014), “Women's Participation and Voice in Community-Based Organizations", Publication Stock No. TIM146448 
Annexure -

Administrative meetings of CBO
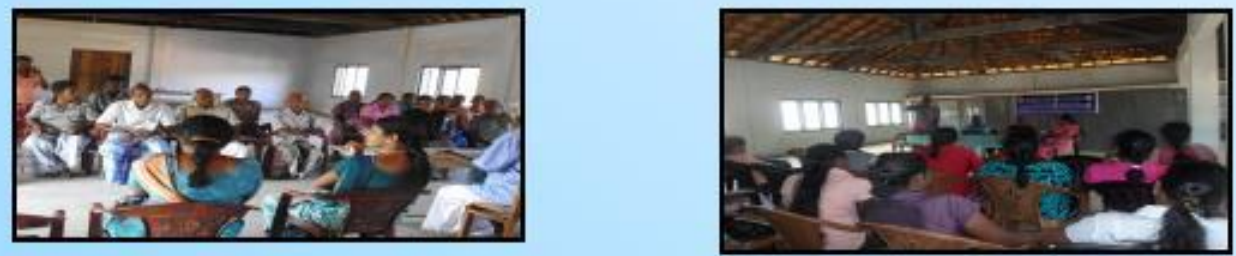

General meetings of CBO
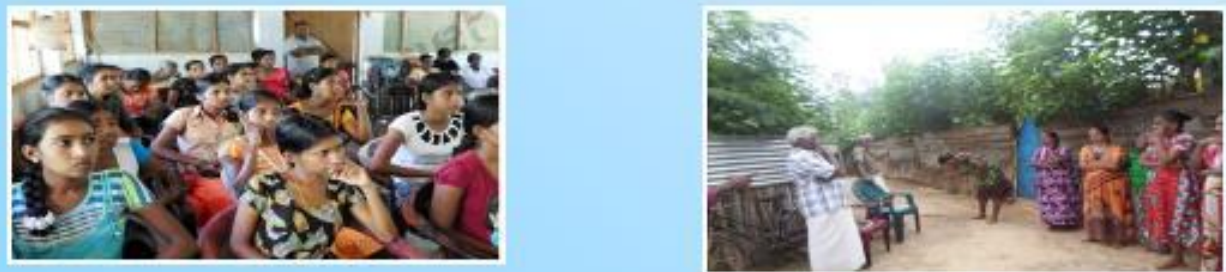

Hygiene awareness programmes organized by $\mathrm{CBO}$
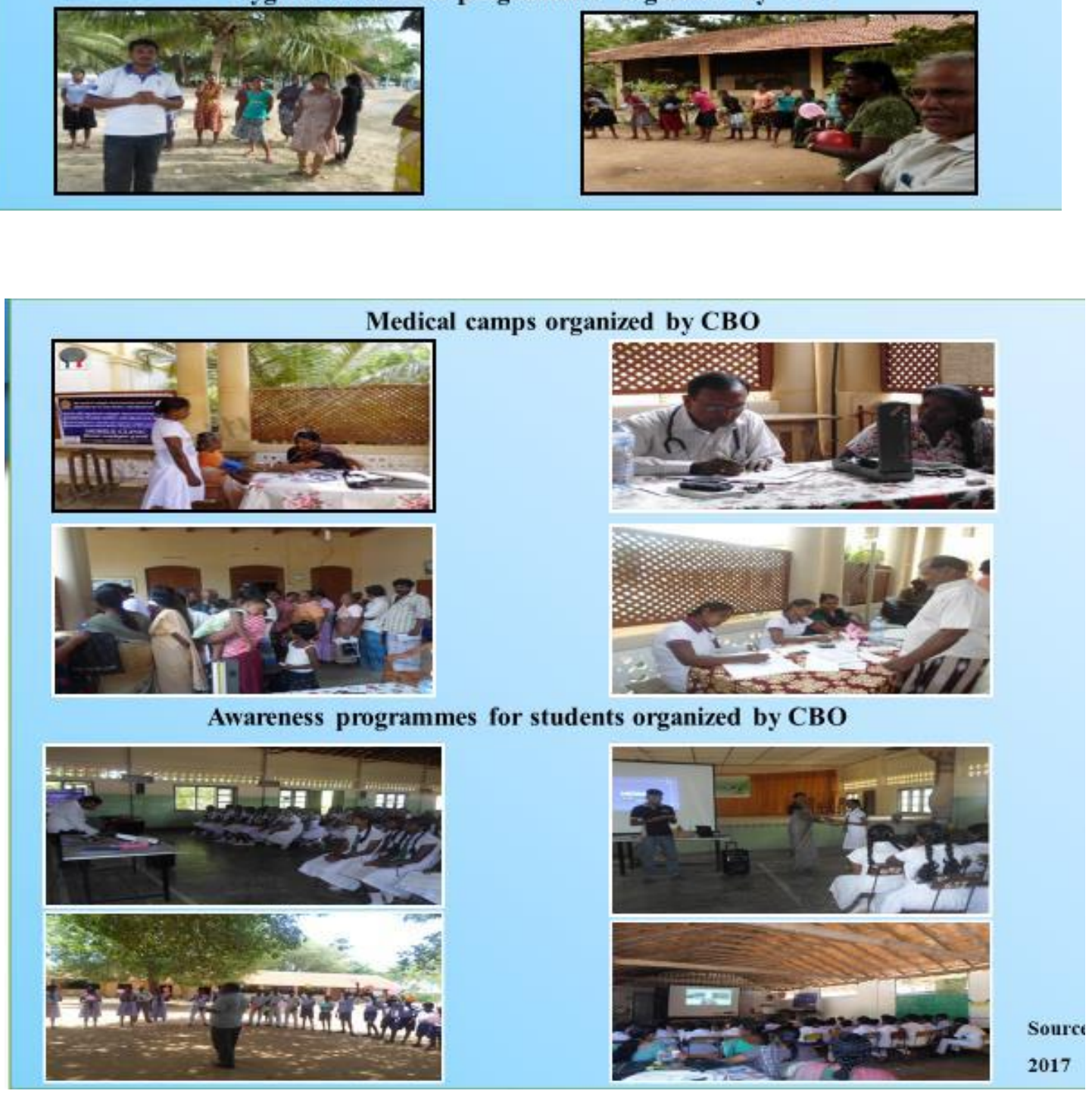
CBO involvement in the construction phase

Digging pits for pipe laying

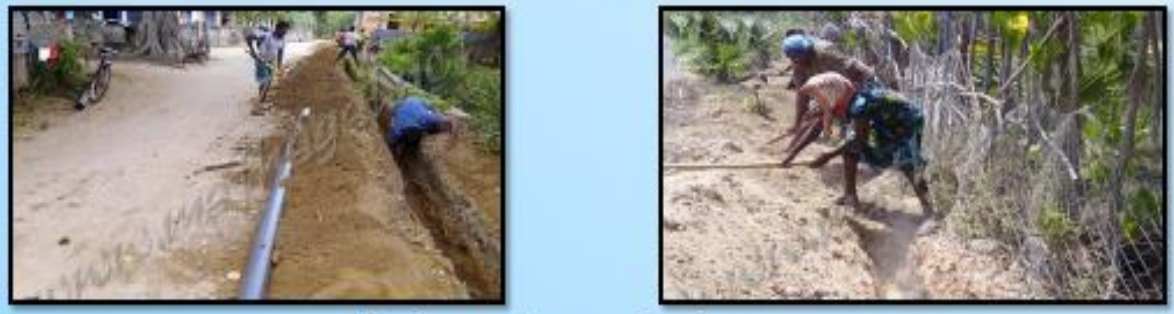

Laying water supply pipes
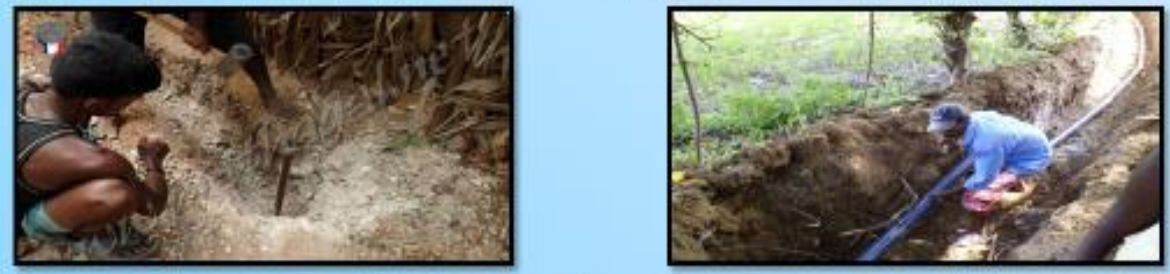

Construction of stand post
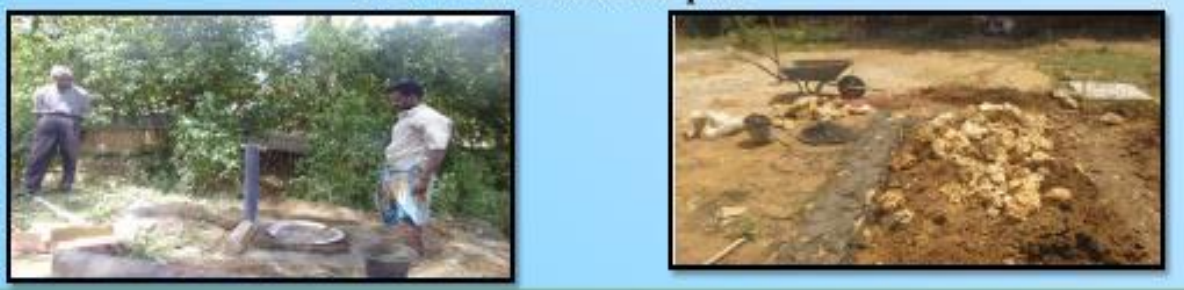

Source-Fi

FEMALE COMMITTEE MEMBERS OF CBOS INVOLVE IN IMPLEMENTATION, OPERATION AND MAINTENANCE PHASES
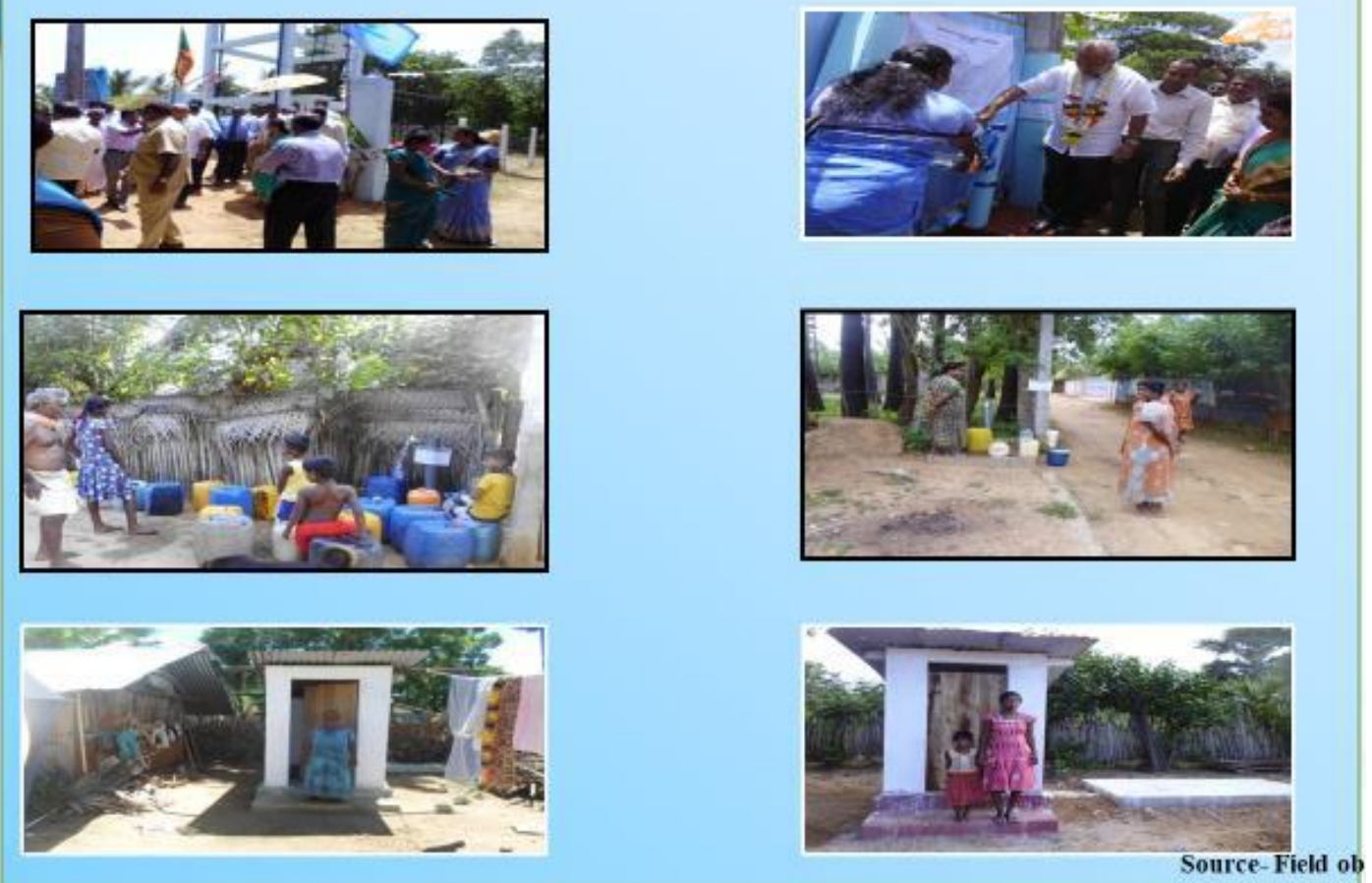

Source: Field Observation (2017) 